\title{
Seleção de rizóbios nativos para guandu, caupi e feijão-de-porco nos tabuleiros costeiros de Sergipe ${ }^{(1)}$
}

\begin{abstract}
Marcelo Ferreira Fernandes ${ }^{(2)}$, Roberta Pereira Miranda Fernandes ${ }^{(3)}$ e Mariangela Hungria ${ }^{(4)}$
Resumo - A inoculação de estirpes de rizóbios em sementes de feijão-de-porco (Canavalia ensiformis), caupi (Vigna unguiculata) e guandu (Cajanus cajan), recomendadas para outras regiões do País, não tem resultado em incrementos nas taxas de fixação biológica de $\mathrm{N}_{2}$ nem no crescimento dessas leguminosas em solos dos tabuleiros costeiros de Sergipe. Os objetivos deste trabalho foram avaliar a eficiência simbiótica de rizóbios nativos dos tabuleiros costeiros associados a essas leguminosas e a tolerância deles a estresses. Das 17 estirpes de rizóbios isoladas e analisadas em casa de vegetação, quatro foram selecionadas para o guandu, sete para o caupi e três para o feijão-de-porco. O número e a massa de nódulos secos por planta correlacionaram-se com a massa da parte aérea seca, a área foliar e o $\mathrm{N}$ total acumulado nas folhas das três leguminosas. Os mesmos rizóbios foram eficientes para o caupi e para o guandu. Três estirpes do guandu (R35, R43 e R45) e duas do caupi (R10 e R17) foram caracterizadas in vitro e todas apresentaram tolerância às concentrações elevadas de ácido nalidíxico, cloranfenicol e tetraciclina, porém, foram sensíveis à estreptomicina e à kanamicina. Todas as estirpes cresceram a $35^{\circ} \mathrm{C}$ e, exceto a R17, toleraram o alumínio $\left(10 \mathrm{mg} \mathrm{L}^{-1}\right)$.
\end{abstract}

Termos para indexação: Cajanus cajan, Canavalia ensiformis, Vigna unguiculata, biologia molecular, fixação de nitrogênio.

\section{Selection of indigenous rhizobia to the cowpea, pigeonpea and jackbean crops in the coastal tableland of Sergipe, Brazil}

\begin{abstract}
The inoculation of rhizobial strains in jackbean (Canavalia ensiformis), cowpea (Vigna unguiculata) and pigeonpea (Cajanus cajan), recommended for other regions of Brazil, has not resulted in increases of biological nitrogen fixation rates and plant growth in soils of the coastal tableland of Sergipe (Brazilian Northeast). The objectives of this work were to evaluate the symbiotic effectiveness of indigenous rhizobia from that coastal tableland associated to these three legumes and their tolerance to stresses. Seventeen rhizobia strains were isolated and evaluated in a greenhouse. Four strains were selected for pigeonpea; seven for cowpea and three for jackbean. Nodules number and dry weight were related to shoot dry weight, leaf area and leaf $\mathrm{N}$ content, in all three legumes. The same strains were efficient for both cowpea and pigeonpea. Three pigeonpea (R35, R43 and R45) and two cowpea (R10 and R17) rhizobia were characterized in vitro and all showed tolerance to high levels of nalidix acid, chloramphenicol and tetracycline; however, they were sensitive to streptomycin and kanamycin. All strains were able to grow at $35^{\circ} \mathrm{C}$ and, except for R17, were tolerant to aluminium $\left(10 \mathrm{mg} \mathrm{L}^{-1}\right)$.
\end{abstract}

Index terms: Cajanus cajan, Canavalia ensiformis, Vigna unguiculata, molecular biology, nitrogen fixation.

(1) Aceito para publicação em 7 de abril de 2003

${ }^{(2)}$ Embrapa-Centro de Pesquisa Agropecuária dos Tabuleiros Costeiros, Caixa Postal 44, CEP 49025-040 Aracaju, SE. E-mail: Marcelo.Fernandes@orst.edu

(3)Universidade Federal de Sergipe, Dep. de Fisiologia, Cidade Universitária Prof. José Aloísio de Campos, Av. Marechal Rondon, s/nô, Jardim Rosa Elze, CEP 49100-000 São Cristóvão, SE. E-mail: fernanro@onid.orst.edu

(4)Embrapa-Centro Nacional de Pesquisa de Soja, Caixa Postal 231, CEP 86001-970 Londrina, PR. Bolsista do CNPq. E-mail: hungria@cnpso.embrapa.br

\section{Introdução}

A inoculação de estirpes de rizóbios em sementes de feijão-de-porco, caupi e guandu, recomendadas para outras regiões do País, não tem resultado em incrementos no crescimento vegetativo, nos teores de $\mathrm{N}$ na planta e na nodulação das raízes em solos dos tabuleiros costeiros de Sergipe (Barreto \& Fernandes, 1998). Esta ausência de resposta à inoculação pode ser conseqüência da baixa adapta- 
bilidade das estirpes às condições edafoclimáticas da região ou incapacidade para colonizar efetivamente as raízes na presença de populações de rizóbios já estabelecidas no solo. Além disso, pelo caráter promíscuo da nodulação destas leguminosas, várias estirpes nativas podem se associar às raízes, dificultando ainda mais a introdução de estirpes alóctones e, com frequiência, tem sido relatada uma relação inversa entre resposta à inoculação e tamanho da população de rizóbios nativos no solo (Weaver \& Frederick, 1974; Thies et al., 1991b).

Além da eficiência simbiótica, a capacidade de sobrevivência no solo e a habilidade competitiva com a população rizobiana nativa ou naturalizada do solo são características altamente desejáveis em estirpes de rizóbios recomendadas para inoculação em leguminosas (Brockwell, 1981). Essas características têm sido freqüentemente relacionadas à maior resistência das estirpes a antibióticos, ao Al e a temperaturas elevadas (Oliveira \& Graham, 1990; Wolff et al., 1991; Xavier et al., 1998). As temperaturas elevadas, que ocorrem frequientemente nos trópicos, afetam diversos estágios da fixação biológica do $\mathrm{N}_{2}$ (FBN), como o crescimento e sobrevivência do rizóbio no solo, troca de sinais moleculares entre os simbiontes, processo de infecção e nodulação e atividade do aparato enzimático para redução do $\mathrm{N}_{2}$ e assimilação da amônia formada (Hungria \& Vargas, 2000). Do mesmo modo, concentrações tóxicas de Al ocorrem em diversos solos intemperizados dos trópicos e afetam todas as etapas da FBN (Hungria \& Vargas, 2000). Contudo, existe variabilidade entre estirpes de rizóbio quanto à tolerância a temperaturas elevadas e ao Al tóxico (Ayanaba et al., 1983; La Favre \& Eaglesham, 1986; Karanja \& Wood, 1988; Wood, 1995; Hungria et al., 1997; Hungria \& Vargas, 2000; Campo \& Wood, 2001).

Os objetivos deste trabalho foram avaliar a eficiência simbiótica de rizóbios nativos dos tabuleiros costeiros de Sergipe inoculados em guandu, caupi e feijão-de-porco e a tolerância deles a estresses.

\section{Material e Métodos}

O isolamento dos rizóbios foi feito em meio de cultura semi-sólido contendo extrato-de-levedura e manitol (YMA, yeast manitol agar), tendo o vermelho Congo como indica- dor (Vincent, 1970), a partir de nódulos de raízes de guandu (Cajanus cajan), feijão-de-porco (Canavalia ensiformis), caupi (Vigna unguiculata) e crotalárias (Crotalaria juncea e C. spectabilis), leguminosas que vêm sendo utilizadas e que foram coletadas em diferentes áreas dos tabuleiros costeiros de Sergipe.

Dos isolados obtidos, foram selecionadas 17 estirpes (Tabela 1), que foram avaliadas quanto aos seus efeitos sobre o crescimento, nodulação e acúmulo de $\mathrm{N}$ em guandu, feijão-de-porco e caupi.

As estirpes foram avaliadas em experimentos realizados em casa de vegetação da Embrapa-Centro de Pesquisa Agropecuária dos Tabuleiros Costeiros, em Aracaju, SE, empregando-se delineamento experimental inteiramente casualizado, com quatro repetições. Além dos 17 rizóbios nativos, foram incluídos um tratamento sem inoculação e outro com inoculação de estirpes recomendadas comercialmente para essas culturas. As estirpes, enviadas pela Embrapa-Centro Nacional de Pesquisa de Agrobiologia, Seropédica, RJ, foram as seguintes: para o caupi, SEMIA 6145 (=BR2001); para o guandu, uma mistura com SEMIA 6156 (=CPAC-IJ) e SEMIA $6157(=\mathrm{BR}$ 2801); para o feijão-de-porco, uma mistura de SEMIA 6156 + SEMIA 6158 (=CPAC 42).

Os procedimentos de implantação, condução e coleta dos experimentos foram idênticos com as três leguminosas, exceto quando mencionado. Utilizaram-se vasos de Leonard

Tabela 1. Estirpes de rizóbios isoladas de plantas de guandu, caupi e feijão-de-porco, locais no Estado de Sergipe, velocidade de crescimento e alteração do $\mathrm{pH}$ em meio de cultura YMA com indicador de azul de bromotimol.

\begin{tabular}{lllcl}
\hline Estirpe & Planta hospedeira & Local & $\begin{array}{c}\text { Velocidade de } \\
\text { crescimento }\end{array}$ & $\mathrm{pH}^{(2)}$ \\
\hline R04 & Guandu & Aracaju & $\mathrm{MR}$ & Neutro \\
R06 & Guandu & Umbaúba & $\mathrm{L}$ & Alcalino \\
R10 & Caupi & Umbaúba & $\mathrm{R}$ & Neutro \\
R14 & Feijão-de-porco & Umbaúba & $\mathrm{L}$ & Alcalino \\
R17 & Caupi & Umbaúba & $\mathrm{L}$ & Alcalino \\
R18 & Guandu & Aracaju & $\mathrm{MR}$ & Neutro \\
R26 & Caupi & N. S. Dores & $\mathrm{R}$ & Ácido \\
R28 & Feijão-de-porco & N. S. Dores & $\mathrm{R}$ & Neutro \\
R30 & Guandu & Umbaúba & $\mathrm{R}$ & Ácido \\
R31 & Guandu & Aracaju & $\mathrm{R}$ & Neutro \\
R33 & Caupi & Aracaju & $\mathrm{R}$ & Ácido \\
R35 & Guandu & N. S. Dores & $\mathrm{L}$ & Neutro \\
R39 & Guandu & Queimadas & $\mathrm{I}$ & Alcalino \\
R43 & Guandu & N. S. Dores & $\mathrm{L}$ & Neutro \\
R45 & Guandu & Aracaju & $\mathrm{L}$ & Alcalino \\
R50 & Crotalaria juncea & Umbaúba & MR & Ácido \\
R51 & C. spectabilis & Umbaúba & $\mathrm{MR}$ & Ácido \\
\hline
\end{tabular}

${ }^{(1)}$ Classes de crescimento determinadas de acordo com o número de dias para que colônias isoladas atingissem $1 \mathrm{~mm}$ de diâmetro: menos de três dias, muito rápido $(\mathrm{MR})$; de três a cinco dias, rápido $(\mathrm{R})$; de seis a sete dias, intermediário (I); de oito a dez dias, lento (L). ${ }^{(2)} \mathrm{pH}$ avaliado ao final de cinco ou dez dias de crescimento das estirpes de crescimento rápido ou lento, respectivamente. 
modificados (Vincent, 1970) com capacidade de $1 \mathrm{~L}$ em cada compartimento. O compartimento superior foi preenchido com vermiculita e o inferior com solução nutritiva isenta de N (Weaver \& Frederick, 1982), sendo o conjunto autoclavado. Três sementes de cada leguminosa, desinfestadas com hipoclorito de sódio a 10\% (6 min), lavadas com água estéril foram semeadas em cada vaso. Uma semana após a semeadura, o desbaste foi realizado, deixando-se apenas uma planta por vaso.

A preparação e padronização dos inóculos foram feitas de acordo com Fernandes \& Fernandes (2000) e a inoculação foi realizada no momento da semeadura utilizando-se $3 \mathrm{~mL}$ de suspensões de rizóbios (aproximadamente $10^{9}$ células $\mathrm{mL}^{-1}$ ). Os vasos dos tratamentos sem inoculação receberam $3 \mathrm{~mL}$ de uma suspensão de rizóbio previamente autoclavada, como controle de nutrientes que pudessem estar disponíveis no meio de cultura. Os compartimentos inferiores dos vasos de Leonard foram completados, a cada quatro dias, com solução nutritiva esterilizada e isenta de nitrogênio. $O$ experimento de caupi foi colhido aos 50 dias após a semeadura (DAS); o de feijão-de-porco aos 55 DAS e o de guandu aos 60 dias após a semeadura.

A área foliar (AF) foi obtida utilizando-se um aparelho Li-Cor (EUA) e a massa da parte aérea seca (MPAS) foi determinada após secagem em estufa a $65^{\circ} \mathrm{C}$ por 72 horas. Os teores de $\mathrm{N}$ nas folhas (NF) foram determinados pelo método de Kjeldhal. Os nódulos foram retirados, contados $(\mathrm{NN})$ e, após secagem em estufa a $65^{\circ} \mathrm{C}$, por 72 horas, pesados para determinação da massa de nódulos secos (MNS).

A estirpe de rizóbio foi considerada eficiente quando os valores médios de AF, MPAS, NN, MNS e NF das plantas submetidas à inoculação foram superiores aos obtidos no tratamento sem inoculação e, simultaneamente, iguais ou superiores aos das leguminosas que receberam inóculos dos rizóbios recomendados para as respectivas espécies.

Os dados foram submetidos à análise de variância e as médias comparadas pelo teste de Tukey a 5\% de probabilidade. Foram determinados os coeficientes de correlação entre as espécies estudadas com relação a MPAS, AF, NN, MNS e NF.

As estirpes R10, R17, R35, R43 e R45, que apresentaram alta eficiência simbiótica para, pelo menos, uma das leguminosas avaliadas, foram selecionadas para a etapa de avaliação da tolerância a estresses.

As avaliações da tolerância dos isolados ao $\mathrm{Al}$ e às temperaturas elevadas, assim como os testes de tolerância aos antibióticos kanamicina, ácido nalidíxico, cloranfenicol, estreptomicina, tetraciclina e ampicilina, foram realizadas conforme descrito por Fernandes \& Fernandes (2000).
Os teores de Al testados no meio YMA foram de 0,5 , 10 e $20 \mathrm{mg} \mathrm{L}^{-1}$, fornecido na forma de $\mathrm{AlK}\left(\mathrm{SO}_{4}\right)_{2} \cdot 12 \mathrm{H}_{2} \mathrm{O}$, e os diâmetros das colônias medidos após sete dias de incubação a $28^{\circ} \mathrm{C}$. Os testes de temperatura também foram realizados em meio YMA e as avaliações do diâmetro das colônias realizadas após sete dias de incubação a $28^{\circ} \mathrm{C}$, $35^{\circ} \mathrm{C} \mathrm{e} 45^{\circ} \mathrm{C}$. Os resultados foram expressos em porcentagem do diâmetro das colônias nos diferentes tratamentos, em comparação aos tratamentos controle (0 mg de $\mathrm{Al} \mathrm{e} 28^{\circ} \mathrm{C}$ ).

A tolerância intrínseca das cinco estirpes aos antibióticos foi determinada pela técnica de gradiente de concentração $\left(0\right.$ a $\left.500 \mu \mathrm{g} \mathrm{mL}^{-1}\right)$ em placa de Petri com meio YMA. A avaliação foi feita após quatro dias de incubação a $28^{\circ} \mathrm{C}$. Quando o crescimento bacteriano ocorreu, atribuíram-se notas de 0 a 3 , respectivamente, às faixas de concentrações de antibióticos de 0 a $125 \mu \mathrm{g} \mathrm{mL}^{-1} ; 126$ a $250 \mu \mathrm{g} \mathrm{mL}^{-1} ; 251$ a $375 \mu \mathrm{g} \mathrm{mL}^{-1}$ ou 376 a $500 \mu \mathrm{g} \mathrm{mL}^{-1}$.

\section{Resultados e Discussão}

Houve diferenças significativas entre as estirpes de rizóbio quanto à capacidade de promover o crescimento vegetativo (MPAS e AF), ao teor de $\mathrm{N}$ foliar (NF) e à nodulação das raízes (NN e MNS) de guandu, caupi e feijão-de-porco (Tabela 2). Quatro estirpes de rizóbios nativos ( $\mathrm{R} 45, \mathrm{R} 14, \mathrm{R} 35$ e R33) foram consideradas eficientes quanto à $\mathrm{FBN}$ para o guandu (Tabela 3); sete (R33, R45, R10, R43, R35, R51 e R14) para o caupi (Tabela 4) e três (R43, R17 e R35) para o feijão-de-porco (Tabela 5). As estirpes utilizadas nos inoculantes comerciais foram consideradas eficientes para o guandu (Tabela 3) e para o caupi (Tabela 4), mas não para o feijão-de-porco (Tabela 5). Comparativamente aos rizóbios nativos considerados eficientes, porém, a mistura comercial para o feijãode-porco foi inferior apenas ao melhor isolado nativo, o R43, com relação à MPAS, AF e NN (Tabela 5). Os resultados obtidos confirmam diferenças na eficiência de estirpes de rizóbios em promover benefícios a diferentes plantas hospedeiras (Peres \& Vidor, 1980; Santillana et al., 1998; Carvalho \& Stamford, 1999; Fernandes \& Fernandes, 2000).

Como o NF dos tratamentos com rizóbios eficientes nas três leguminosas estudadas foi superior ao das plantas sem inoculação, considerou-se que a grande parte do $\mathrm{N}$ das plantas tenha origem na FBN. Os valores mais elevados de $\mathrm{N}$ nas plantas de feijão- 
de-porco não submetidas à inoculação foram provenientes da grande reserva de $\mathrm{N}$ nas sementes desta espécie, avaliada entre 46 e $70 \mathrm{mg}$.

Os valores obtidos para MNS e NN apresentaram alta correlação com as variáveis MPAS, AF e NF, nas três leguminosas estudadas (Tabela 6); na análise destas correlações, os dados das plantas sem inoculação foram desconsiderados. Correlações positivas e significativas entre a massa nodular e a quantidade de $\mathrm{N}$ fixado biologicamente foram relatadas também por Döbereiner et al. (1966), Santos (1987), Bohrer \& Hungria (1998) e Fernandes \& Fernandes (2000).
Os valores de MPAS, AF, MNS e NF de caupi e guandu mostraram-se significativa e positivamente correlacionados, indicando que os isolados benéficos para uma dessas leguminosas também o são para a outra (Tabela 7). Correlações significativas foram observadas em relação a algumas variáveis, por exemplo, MNS, quando os dados de caupi e guandu foram correlacionados aos do feijão-de-porco. Diferenças no grau de compartilhamento de rizóbios eficientes entre leguminosas também foram observadas por Thies et al. (1991a). Segundo esses autores, Macroptilium atropurpureum foi, quando compa-

Tabela 2. Análise de variância da massa da parte aérea seca (MPAS), da área foliar (AF), da massa de nódulos secos (MNS), do número de nódulos (NN) e do $\mathrm{N}$ total acumulado nas folhas (NF) de guandu, caupi e feijão-de-porco submetidos à inoculação de diferentes isolados de rizóbios.

\begin{tabular}{|c|c|c|c|c|c|c|}
\hline Fonte de variação & $\overline{\text { GL }}$ & MPAS & $\overline{\mathrm{AF}}$ & MNS & $\mathrm{NN}^{(1)}$ & $\mathrm{NF}$ \\
\hline & \multicolumn{6}{|c|}{ Feijão-de-porco } \\
\hline Rizóbio & 18 & $9,923 * *$ & $125.464,041 * *$ & $0,07287 * *$ & $48,0197 * *$ & $8.445,26 * *$ \\
\hline Resíduo & 57 & 1,213 & $19.821,474$ & 0,00530 & 7,1926 & $1.027,43$ \\
\hline \multirow[t]{2}{*}{$\mathrm{CV}(\%)$} & & 17.59 & 16,13 & 29.42 & 31,35 & 32,83 \\
\hline & \multicolumn{6}{|c|}{ Caupi } \\
\hline Rizóbio & 18 & $3,486 * *$ & $129.109,722 * *$ & $0,00793 * *$ & $15,3484 * *$ & $2.336,49 * *$ \\
\hline$\underline{\text { Resíduo }}$ & 57 & 0,205 & $10.671,145$ & 0,00075 & 2,1331 & 184,32 \\
\hline \multirow{2}{*}{ CV $(\%)$} & & 27.37 & 26,10 & 31,62 & 27.75 & 32,52 \\
\hline & \multicolumn{6}{|c|}{ Guandu } \\
\hline Rizóbio & 18 & $2,509^{* *}$ & $57.211,11 * *$ & $0,01458 * *$ & $29,5518 * *$ & $1.692,13 * *$ \\
\hline Resíduo & 57 & 0.273 & 7.594 .06 & 0.00148 & 7.1926 & 161.46 \\
\hline CV (\%) & & 49,09 & 51,56 & 53,10 & 35,34 & 53,27 \\
\hline
\end{tabular}

(1) Dados transformados para $\sqrt{\mathrm{NN}^{*} *}$ Significativo a $1 \%$ de probabilidade.

Tabela 3. Massa da parte aérea seca (MPAS), área foliar (AF), número e massa de nódulos secos (NN e MNS) e N total acumulado nas folhas (NF) de guandu submetido à inoculação de diferentes rizóbios e cultivado em vasos de Leonard ${ }^{(1)}$.

\begin{tabular}{|c|c|c|c|c|c|}
\hline Estirpe $^{(2)}$ & MPAS (g planta $\left.{ }^{-1}\right)$ & $\mathrm{AF}\left(\mathrm{cm}^{2}\right.$ planta $\left.{ }^{-1}\right)$ & $\mathrm{NN}^{(3)}\left(\mathrm{n}^{0}\right.$ planta $\left.^{-1}\right)$ & MNS (g planta ${ }^{-1}$ ) & $\mathrm{NF}$ (mg planta $\left.{ }^{-1}\right)$ \\
\hline $\mathrm{T} 1$ & $2,68 \mathrm{a}$ & $388 \mathrm{a}$ & $47 \mathrm{ab}$ & $0,130 \mathrm{abc}$ & $66,66 a$ \\
\hline R45 & $2,12 \mathrm{ab}$ & $365 a$ & $66 \mathrm{a}$ & $0,170 \mathrm{a}$ & $52,07 \mathrm{ab}$ \\
\hline R14 & $2,08 \mathrm{ab}$ & $310 \mathrm{ab}$ & $42 \mathrm{abc}$ & $0,160 \mathrm{a}$ & $51,26 a b c$ \\
\hline R35 & 1,68abcd & $255 \mathrm{abc}$ & 35abcd & $0,120 \mathrm{abc}$ & $43,02 \mathrm{abcd}$ \\
\hline R33 & $1,75 \mathrm{abc}$ & $315 \mathrm{ab}$ & 37abcd & $0,140 \mathrm{ab}$ & 41,97abcd \\
\hline R06 & $1,80 \mathrm{abc}$ & 251abcd & $43 \mathrm{ab}$ & $0,130 \mathrm{abc}$ & 37,83abcde \\
\hline R17 & 1,45 abcde & 227abcd & 32abcd & $0,120 \mathrm{abc}$ & 37,54abcde \\
\hline $\mathrm{R} 43$ & $1,66 \mathrm{abcd}$ & 229abcd & 36abcd & $0,120 \mathrm{abc}$ & $33,37 \mathrm{bcdef}$ \\
\hline R26 & 0,86 bcde & 164abcd & $8 \mathrm{defg}$ & $0,070 \mathrm{abcd}$ & $18,47 \mathrm{cdef}$ \\
\hline R28 & 0,48 cde & $89 \mathrm{bcd}$ & $17 \mathrm{bcdef}$ & $0,030 \mathrm{~cd}$ & $14,78 \mathrm{def}$ \\
\hline R10 & 0,67 cde & $125 \mathrm{bcd}$ & 26abcde & $0,060 \mathrm{bcd}$ & $13,79 \mathrm{def}$ \\
\hline R50 & $0,65 \mathrm{cde}$ & $114 \mathrm{bcd}$ & 10cdefg & $0,050 \mathrm{bcd}$ & $11,76 \mathrm{def}$ \\
\hline R51 & $0,57 \mathrm{cde}$ & $102 \mathrm{bcd}$ & 6efg & $0,030 \mathrm{~cd}$ & $10,08 \mathrm{def}$ \\
\hline R18 & $0,53 \mathrm{cde}$ & $76 \mathrm{~cd}$ & $1 \mathrm{fg}$ & $0,001 \mathrm{~d}$ & $5,85 \mathrm{ef}$ \\
\hline R39 & $0,32 \mathrm{de}$ & $50 \mathrm{~cd}$ & $2 \mathrm{fg}$ & $0,010 \mathrm{~d}$ & $4,11 \mathrm{f}$ \\
\hline R04 & $0,33 \mathrm{de}$ & $53 \mathrm{~cd}$ & $2 \mathrm{fg}$ & $0,030 \mathrm{~cd}$ & $4,01 \mathrm{f}$ \\
\hline $\mathrm{T} 2$ & $0,23 \mathrm{e}$ & $34 \mathrm{~cd}$ & $0 \mathrm{~g}$ & $0,000 \mathrm{~d}$ & $2,75 f$ \\
\hline R31 & $0,22 \mathrm{e}$ & $36 \mathrm{~cd}$ & $0 \mathrm{~g}$ & $0,000 \mathrm{~d}$ & $2,40 \mathrm{f}$ \\
\hline R30 & $0,11 \mathrm{e}$ & $24 \mathrm{~d}$ & $0 \underline{g}$ & $0,000 \mathrm{~d}$ & $1,40 \mathrm{f}$ \\
\hline
\end{tabular}


rada a Arachis hypogaea e Phaseolus lunatus, a espécie que apresentou maior grau de semelhança com o caupi quanto à resposta à inoculação de rizóbios isolados desta última espécie. O grau de compartilhamento de rizóbios eficientes entre leguminosas do "grupo miscelânea do caupi" foi, inclusive, sugerido como parâmetro na separação dessas espécies em grupos de efetividade (Burton,
1979). De acordo com essa separação, hospedeiros pertencentes a um mesmo grupo de efetividade responderiam de modo similar à inoculação de um dado isolado de rizóbio.

As cinco estirpes selecionadas na avaliação da tolerância a estresses in vitro apresentaram tolerância elevada ao ácido nalidíxico, ao cloranfenicol e à tetraciclina, e sensibilidade à kanamicina e à

Tabela 4. Massa da parte aérea seca (MPAS), área foliar (AF), número e massa de nódulos secos (NN e MNS) e N total acumulado nas folhas (NF) de caupi submetido à inoculação de diferentes rizóbios e cultivado em vasos de Leonard ${ }^{(1)}$.

\begin{tabular}{|c|c|c|c|c|c|}
\hline Estirpe $^{(2)}$ & MPAS (g planta $\left.{ }^{-1}\right)$ & $\mathrm{AF}\left(\mathrm{cm}^{2}\right.$ planta $\left.{ }^{-1}\right)$ & $\mathrm{NN}^{(3)}\left(\mathrm{n}^{0}\right.$ planta $\left.^{-1}\right)$ & MNS (g planta ${ }^{-1}$ ) & $\mathrm{NF}$ (mg planta ${ }^{-1}$ ) \\
\hline $\mathrm{T} 1$ & $2,78 \mathrm{ab}$ & $617 \mathrm{ab}$ & $29 \mathrm{abc}$ & $0,09 \mathrm{abcde}$ & $80,96 \mathrm{a}$ \\
\hline R33 & $3,24 \mathrm{a}$ & $668 \mathrm{a}$ & $38 \mathrm{ab}$ & $0,16 a$ & $69,00 \mathrm{ab}$ \\
\hline R45 & $3,06 \mathrm{a}$ & $645 a$ & $59 a$ & $0,16 a$ & $66,67 \mathrm{abc}$ \\
\hline R10 & $2,97 \mathrm{a}$ & $619 \mathrm{ab}$ & $42 \mathrm{ab}$ & $0,13 a b c$ & $74,84 \mathrm{ab}$ \\
\hline R43 & $2,43 \mathrm{abcd}$ & 450abcd & $44 \mathrm{ab}$ & $0,14 \mathrm{ab}$ & $72,38 \mathrm{ab}$ \\
\hline $\mathrm{R} 35$ & $2,65 \mathrm{abcc}$ & $587 \mathrm{ab}$ & $37 \mathrm{ab}$ & $0,14 \mathrm{ab}$ & $65,37 \mathrm{abc}$ \\
\hline R51 & $1,44 \mathrm{def}$ & $359 \mathrm{bcd}$ & $38 \mathrm{ab}$ & 0,09 abcde & $46,78 \mathrm{abcd}$ \\
\hline R14 & 1,77 bcde & $455 \mathrm{abc}$ & $39 \mathrm{ab}$ & 0,11 abcd & 46,39abcd \\
\hline R06 & $1,65 \mathrm{bcde}$ & 458abc & $12 \mathrm{bcd}$ & $0,07 \mathrm{bcdefg}$ & $45,27 \mathrm{bcd}$ \\
\hline R50 & $1,50 \mathrm{cdef}$ & 409abcd & $54 \mathrm{a}$ & 0,08 bcde & $39,69 \mathrm{bcde}$ \\
\hline R17 & $1,28 \mathrm{def}$ & $353 \mathrm{bcd}$ & $64 a$ & $0,07 \mathrm{bcdefg}$ & $32,75 \mathrm{cde}$ \\
\hline R31 & $1,30 \mathrm{def}$ & $355 \mathrm{bcd}$ & $38 \mathrm{ab}$ & 0,09abcde & $32,63 \mathrm{cde}$ \\
\hline R30 & $1,24 \mathrm{ef}$ & $369 \mathrm{bcd}$ & $25 \mathrm{abc}$ & $0,07 \mathrm{bcdefg}$ & $28,61 \mathrm{de}$ \\
\hline R04 & $1,00 \mathrm{ef}$ & $268 \mathrm{cde}$ & 19abcd & $0,06 \mathrm{cdefg}$ & $25,65 \mathrm{de}$ \\
\hline $\mathrm{R} 26$ & $0,97 \mathrm{ef}$ & 291cde & $33 \mathrm{ab}$ & 0,08 bcdef & $24,03 \mathrm{de}$ \\
\hline $\mathrm{R} 28$ & $0,73 \mathrm{ef}$ & $184 \mathrm{de}$ & $9 \mathrm{bcd}$ & $0,04 \mathrm{efg}$ & $19,83 \mathrm{de}$ \\
\hline R39 & $0,59 \mathrm{ef}$ & $283 \mathrm{cde}$ & $13 \mathrm{bcd}$ & $0,05 \mathrm{defg}$ & $12,14 \mathrm{de}$ \\
\hline $\mathrm{R} 18$ & $0,37 \mathrm{f}$ & $70 \mathrm{e}$ & $4 \mathrm{~cd}$ & $0,01 \mathrm{fg}$ & $5,78 \mathrm{e}$ \\
\hline $\mathrm{T} 2$ & $0.41 \mathrm{f}$ & $77 \mathrm{e}$ & $1 \mathrm{~d}$ & $0.00 \mathrm{~g}$ & $4.37 \mathrm{e}$ \\
\hline
\end{tabular}

Tabela 5. Massa da parte aérea seca (MPAS), área foliar (AF), número e massa de nódulos secos (NN e MNS) e N total acumulado nas folhas (NF) de feijão-de-porco submetido à inoculação de diferentes rizóbios e cultivado em vasos de Leonard ${ }^{(1)}$

\begin{tabular}{|c|c|c|c|c|c|}
\hline Estirpe $^{(2)}$ & MPAS (g planta $^{-1}$ ) & $\mathrm{AF}\left(\mathrm{cm}^{2}\right.$ planta $\left.{ }^{-1}\right)$ & $\mathrm{NN}^{(3)}\left(\mathrm{n}^{0}\right.$ planta $\left.^{-1}\right)$ & MNS (g planta ${ }^{-1}$ ) & NF (mg planta ${ }^{-1}$ ) \\
\hline R43 & $11,30 \mathrm{a}$ & $1.299 \mathrm{a}$ & $246 a$ & $0,43 \mathrm{ab}$ & $186,78 \mathrm{a}$ \\
\hline R17 & $7,62 b$ & $895 \mathrm{bcd}$ & 101abcd & $0,37 \mathrm{abc}$ & $157,30 \mathrm{ab}$ \\
\hline R35 & $7,61 b$ & $1.064 \mathrm{ab}$ & $211 \mathrm{ab}$ & $0,29 b c$ & $145,93 \mathrm{ab}$ \\
\hline R10 & $7,07 b \mathrm{c}$ & $1.010 \mathrm{abcd}$ & $74 \mathrm{bcd}$ & $0,24 \mathrm{bcde}$ & $148,05 \mathrm{ab}$ \\
\hline R30 & $7,07 \mathrm{bc}$ & $1.014 \mathrm{abc}$ & 86abcd & 0,28 bcd & $142,20 \mathrm{abc}$ \\
\hline R06 & $6,58 \mathrm{bc}$ & $1.079 \mathrm{ab}$ & 79abcd & $0,37 \mathrm{abc}$ & $125,17 \mathrm{abcd}$ \\
\hline $\mathrm{R} 33$ & $6,07 b c$ & 970abcd & 96abcd & 0,21 cdef & 124,88 abdd \\
\hline $\mathrm{T} 1$ & $5,25 \mathrm{bc}$ & $827 \mathrm{bcde}$ & $63 \mathrm{bcde}$ & $0,33 \mathrm{abc}$ & 106,81abcde \\
\hline R50 & $5,91 b c$ & $860 \mathrm{bcde}$ & $70 \mathrm{bcd}$ & $0,28 \mathrm{bcd}$ & $101,56 \mathrm{bcde}$ \\
\hline R51 & $5,37 \mathrm{bc}$ & 813 bcde & 97abcd & $0,32 \mathrm{abc}$ & 94,48 bcde \\
\hline R45 & $6,40 \mathrm{bc}$ & $916 \mathrm{bcd}$ & $138 \mathrm{abc}$ & $0,49 \mathrm{a}$ & 92,83 bcde \\
\hline R14 & $6,48 b c$ & 898bcd & 90abcd & $0,28 \mathrm{bcd}$ & 81,04 bcde \\
\hline $\mathrm{R} 31$ & $6,28 b c$ & 810 bcde & $70 \mathrm{bcd}$ & $0,30 \mathrm{abc}$ & 79,17 bcde \\
\hline R39 & $4,20 \mathrm{c}$ & 725 bcde & $27 \mathrm{cde}$ & 0,22 cdef & $60,31 \mathrm{cde}$ \\
\hline R18 & $6,25 b c$ & 802 bcde & $56 \mathrm{cde}$ & $0,08 \mathrm{efg}$ & $56,58 \mathrm{de}$ \\
\hline $\mathrm{R} 28$ & $4,71 \mathrm{c}$ & $685 \mathrm{cde}$ & 58 bcde & 0,07 efg & $42,90 \mathrm{de}$ \\
\hline $\mathrm{R} 26$ & $4,88 \mathrm{bc}$ & $644 \mathrm{de}$ & $11 \mathrm{de}$ & $0,04 \mathrm{fg}$ & $39,85 \mathrm{e}$ \\
\hline $\mathrm{T} 2$ & $4,71 \mathrm{c}$ & $550 \mathrm{e}$ & $1 \mathrm{e}$ & $0,01 \mathrm{~g}$ & $35,69 \mathrm{e}$ \\
\hline $\mathrm{R} 04$ & $5,19 b c$ & $717 \mathrm{bcde}$ & $33 \mathrm{cde}$ & $0,10 \mathrm{defg}$ & $33,31 \mathrm{e}$ \\
\hline
\end{tabular}

${ }^{(1)}$ Emcada coluna, médias seguidas pelas mesmas letras não diferem entre si pelo teste de Tukey a $5 \%$ de probabilidade. ${ }^{(2)} \mathrm{T} 1:$ testemunha submetida à inoculação de estirpes recomendadas comercialmente (SEMIA 6156 + SEMIA 6158); T2: testemunha sem inoculação. ${ }^{\left({ }^{3}\right)}$ Análise estatística realizada com dados convertidos para $\sqrt{\mathrm{NN}}$. 
estreptomicina (Tabela 8). Com exceção da R10, todos os demais rizóbios também foram tolerantes a concentrações elevadas de ampicilina (> $\left.250 \mathrm{mg} \mathrm{L}^{-1}\right)$. Resultados semelhantes foram obtidos por Xavier et al. (1998) com rizóbios de caupi isolados no Nordeste do Brasil. Conforme esses autores, das 17 classes de rizóbios, agrupadas de acordo com a resistência a oito antibióticos, 14 foram sensíveis a doses superiores a $125 \mathrm{mg} \mathrm{L}^{-1}$ de estreptomicina kanamicina. Destas 17 classes, seis foram sensíveis a $125 \mathrm{mg} \mathrm{L}^{-1}$ de cloranfenicol e de tetraciclina, e sete foram sensíveis à mesma concentração do ácido nalidíxico.

As estirpes R10, R35, R43 e R45 não apresentaram redução do crescimento na presença de $5 \mathrm{e}$ $10 \mathrm{mg} \mathrm{L}^{-1}$ de Al, em comparação ao controle isento de A 1 ; no entanto, nenhum crescimento foi observado com $20 \mathrm{mg} \mathrm{L}^{-1}$ de alumínio. A estirpe R17 foi a mais sensível dos cinco rizóbios caracterizados, não apresentando crescimento em $10 \mathrm{mg} \mathrm{L}^{-1}$ de alumínio. Não houve relação entre a reação ácida ou alcalina

Tabela 6. Coeficientes de correlação do número e massa de nódulos secos por planta (NN e MNS) com a massa da parte aérea seca (MPAS), a área foliar (AF) e o $\mathrm{N}$ total acumulado nas folhas (NF) de guandu, caupi e feijão-de$\operatorname{porco}^{(1)}$.

\begin{tabular}{llcc}
\hline Correlacão & Guandu & Caupi & Feijão-de-porce \\
\hline MNS x MPAS & $0,918^{* *}$ & $0,876^{* *}$ & $0,518^{* *}$ \\
MNS x AF & $0,917^{* *}$ & $0,885^{* *}$ & $0,628^{* *}$ \\
MNS x NF & $0,904^{* *}$ & $0,818^{* *}$ & $0,671^{* *}$ \\
NN x MPAS & $0,842^{* *}$ & $0,542^{* *}$ & $0,645^{* *}$ \\
NN x AF & $0,848^{* *}$ & $0,607^{* *}$ & $0,686^{* *}$ \\
NN x NF & $0.860^{* *}$ & $0.555^{* *}$ & $0.641^{* *}$ \\
\hline
\end{tabular}

${ }^{(1)}$ Com relação à variável NN a análise de correlação foi realizada com os dados convertidos para $\sqrt{\mathrm{NN}^{*} *}$ Significativo a $1 \%$ de probabilidade pelo teste $\mathrm{t}$.

Tabela 7. Coeficientes de correlação dos dados da massa de nódulos secos (MNS), do número de nódulos (NN), da massa da parte aérea seca (MPAS), da área foliar (AF) e do $\mathrm{N}$ total acumulado nas folhas (NF) entre guandu e caupi $(\mathrm{GxC})$, guandu e feijão-de-porco (GxFP) e caupi e feijãode-porco $(\mathrm{CxFP})^{(1)}$.

\begin{tabular}{|c|c|c|c|}
\hline Parâmetro & $\mathrm{GxC}$ & GxFP & $\mathrm{CxEP}$ \\
\hline MNS & $0,69 * *$ & $0,52 *$ & $0,57 *$ \\
\hline NN & $0,46^{\mathrm{ns}}$ & $0,54 *$ & $0,34^{\mathrm{ns}}$ \\
\hline MPAS & $0,65^{* *}$ & $0,44^{\mathrm{ns}}$ & $0,47^{\mathrm{ns}}$ \\
\hline $\mathrm{AF}$ & $0,69 * *$ & $0,45^{\mathrm{ns}}$ & $0,60 *$ \\
\hline $\mathrm{NF}$ & $0.63 * *$ & $0.40^{\mathrm{ns}}$ & $0.69 * *$ \\
\hline
\end{tabular}

Pesq. agropec. bras., Brasília, v. 38, n. 7, p. 835-842, jul. 2003 em meio de cultura contendo manitol (Tabela 1) como fonte de $\mathrm{C}$ e a tolerância ao alumínio. Diferenças entre estirpes de rizóbio quanto à tolerância ao $\mathrm{Al}$ têm sido relatadas (Ayanaba et al., 1983; Hungria \& Vargas, 2000; Campo \& Wood, 2001), contudo, os mecanismos envolvidos nessa tolerância ainda não estão totalmente esclarecidos. Estudos compilados por Johnson \& Wood (1990) e Wood (1995) indicaram que a ação dos íons Al ocorreria pela sua ligação ao DNA, interferindo na divisão celular. Contudo, tanto estirpes tolerantes como não tolerantes não apresentaram diferenças na ligação ao DNA, de modo que devem existir outros mecanismos de reparo do DNA em estirpes tolerantes (Johnson \& Wood, 1990; Wood, 1995). O mais provável, porém, é que o Al interfira em vários mecanismos do rizóbio, tanto em vida livre como em simbiose (Hungria \& Vargas, 2000), podendo atuar, até mesmo, como agente mutagênico (Octive et al., 1991).

Quanto à temperatura, o crescimento das cinco estirpes não foi alterado a $35^{\circ} \mathrm{C}$, comparativamente à temperatura de $28^{\circ} \mathrm{C}$. Apenas a estirpe R10 cresceu a $45^{\circ} \mathrm{C}$ e o diâmetro das colônias nesta temperatura foi equivalente à metade do observado quando a bactéria foi incubada a $28^{\circ} \mathrm{C}$. Temperaturas elevadas têm, freqüentemente, representado um dos principais fatores limitantes à FBN em regiões tropicais, uma vez que afetam praticamente todas as etapas de crescimento do rizóbio e das plantas hospedeiras, sendo os efeitos ainda mais drástico na simbiose (Hungria \& Vargas, 2000). Tem-se considerado, tradicionalmente, que os limites de temperatura para a FBN com leguminosas tropicais se situam entre $27^{\circ} \mathrm{C}$ e $40^{\circ} \mathrm{C}$ (Gibson, 1971; Hungria \& Vargas, 2000). Existem diversos relatos sobre diferenças entre espécies e estirpes de rizóbio quanto à tolerância a temperaturas elevadas (La Favre \& Eaglesham, 1986; Karanja \& Wood, 1988; Hungria et al., 1997; Hungria \& Vargas, 2000), contudo, uma relação entre a localização geográfica (locais com temperaturas elevadas) e essa tolerância não é evidente (Karanja \& Wood, 1988). Embora haja indicação de que a habilidade de crescimento in vitro de uma estirpe não está necessariamente relacionada com a sua capacidade de FBN nas mesmas condições (La Favre \& Eaglesham, 1986; Karanja \& Wood, 1988), a tolerância excepcional de algumas estirpes, como a R10, observada neste tra- 
Tabela 8. Tolerância intrínseca a antibióticos de cinco isolados de rizóbios nativos dos tabuleiros costeiros, determinada pelo método do gradiente em placa, com concentrações variando de 0 a $500 \mu \mathrm{g} \mathrm{mL}^{-1}$ (1).

\begin{tabular}{|c|c|c|c|c|c|c|}
\hline Estirne & Ácido nalidúxico & Cloranfenicol & Tetraciclina & Amnicilina & Estrentomicina & Kanamicina \\
\hline R10 & 3 & 3 & 3 & 0 & 0 & 0 \\
\hline R17 & 3 & 3 & 3 & 3 & 0 & 0 \\
\hline R35 & 3 & 3 & 3 & 3 & 1 & 0 \\
\hline R43 & 3 & 3 & 3 & 2 & 0 & 0 \\
\hline $\mathrm{R} 45$ & 3 & 3 & 3 & 3 & 0 & 0 \\
\hline
\end{tabular}

balho representa o primeiro estágio de seleção para a região dos tabuleiros costeiros de Sergipe, onde freqüentemente o solo atinge temperaturas consideradas limitantes à fixação biológica do nitrogênio. O desempenho simbiótico observado em substrato estéril neste trabalho deve ser confirmado, a campo, para que as estirpes possam ser recomendadas como inoculantes para o guandu, o caupi e o feijão-deporco.

\section{Conclusão}

É possível selecionar estirpes de rizóbios nativos dos tabuleiros costeiros capazes de estabelecer uma simbiose efetiva com guandu, caupi e feijão-de-porco.

\section{Agradecimentos}

À Fundação Banco do Brasil, pelo financiamento de parte deste trabalho; a J.A. Nascimento, C.A. Oliveira e H.B. Santos, pelo apoio na condução do experimento na casa de vegetação e nas análises laboratoriais; às Dras. Maria de Fátima Loureiro (Universidade Federal de Mato Grosso) e Iêda de C. Mendes (Embrapa-Centro de Pesquisa Agropecuária dos Cerrados), pelas sugestões no manuscrito.

\section{Referências}

AYANABA, A.; ASANUMA, S.; MUNNS, D. N. An agar plate method for rapid screening of Rhizobium for tolerance to acid-aluminium stress. Soil Science Society of America Journal, Madison, v. 47, p. 256-258, 1983.

BARRETO, A. C.; FERNANDES, M. F. Recomendação de leguminosas para adubação verde em solos dos tabuleiros costeiros. Aracaju: Embrapa-CPACT, 1998. 5 p. (Comunicado Técnico, 28).

BOHRER, T. R. J.; HUNGRIA, M. Avaliação de cultivares de soja quanto à fixação biológica do nitrogênio. Pes- quisa Agropecuária Brasileira, Brasília, v. 33, n. 6, p. 937-952, jun. 1998.

BROCKWELL, J. Can inoculant strains ever compete successfully with established soil populations? In: GIBSON, A. H.; NEWTON, W. E. (Ed.). Current perspectives in nitrogen. Amsterdam: North Holland/ Elsevier, 1981. p. 277-315.

BURTON, J. C. Rhizobium species. In: PEPPLER, H. J.; PERLMAN, D. (Ed.). Microbial technology: microbial processes. $2^{\text {nd }}$ ed. New York: Academic, 1979. v. 1, p. 29-58.

CAMPO, R. J.; WOOD, M. Residual effects of successive exposure of soybean Bradyrhizobium strains to aluminum on solid defined medium. Pesquisa Agropecuária Brasileira, Brasília, v. 36, n. 11, p. 1399-1407, nov. 2001.

CARVALHO, F. G.; STAMFORD, N. P. Fixação do $\mathrm{N}_{2}$ em leucena (Leucaena leucocephala) em solo da região semi-árida brasileira submetido à salinização. Revista Brasileira de Ciência do Solo, Viçosa, MG, v. 23, p. 237$243,1999$.

DÖBEREINER, J.; ARRUDA, N. B.; PENTEADO, A. F. Avaliação da fixação do nitrogênio em leguminosas pela regressão do $\mathrm{N}$ total das plantas sobre o peso de nódulos. Pesquisa Agropecuária Brasileira, Rio de Janeiro, v. 1, p. 233-237, 1966.

FERNANDES, M. F.; FERNANDES, R. P. M. Seleção inicial e caracterização parcial de rizóbios de tabuleiros costeiros quando associados ao guandu. Revista Brasileira de Ciência do Solo, Viçosa, MG, v. 24, p. 321-327, 2000.

GIBSON, A. H. Factors in the physical and biological environment affecting nodulation and nitrogen fixation by legumes. Plant and Soil, Dordrecht, p. 139-152, 1971. Special volume.

HUNGRIA, M.; VARGAS, M. A. T. Environmental factors affecting $\mathrm{N}_{2}$ fixation in grain legumes in the tropics, with an emphasis on Brazil. Field Crops Research, Amsterdam, v. 65, p. 151-164, 2000. 
HUNGRIA, M.; VARGAS, M. A. T.; ARAUJO, R. S. Fixação biológica do nitrogênio em feijoeiro. In: VARGAS, M. A. T.; HUNGRIA, M. (Ed.). Biologia dos solos dos Cerrados. Planaltina: Embrapa-CPAC, 1997. p. 189-295.

JOHNSON, A. C.;WOOD, M. DNA: a possible site of action of aluminium in Rhizobium spp. Applied and Environmental Microbiology, Washington, v. 56, p. 3629-3633, 1990.

KARANJA, N. K.; WOOD, M. Selecting Rhizobium phaseoli strains for use with beans (Phaseolus vulgaris L.) in Kenya: tolerance of high temperature and antibiotic resistance. Plant and Soil, Dordrecht, v. 112, p. 15-22, 1988.

LA FAVRE, A. K.; EAGLESHAM, A. R. J. The effects of high temperatures on soybean nodulation and growth with different strains of bradyrizobia. Canadian Journal of Microbiology, Ottawa, v. 32, p. 22-27, 1986.

OCTIVE, J. C.; WOOD, M.; JOHNSON, A. C. Mutagenic effects of aluminium. Mutation Research - DNA Repair, Amsterdam, v. 264, p. 135-137, 1991.

OLIVEIRA, L. A.; GRAHAM, P. H. Evaluation of strain competitiveness in Rhizobium leguminosarum bv. phaseoli using a nod+ fix- natural mutant. Archives of Microbiology, Berlin, v. 54, p. 305-310, 1990.

PERES, J. R. R.; VIDOR, C. Seleção de estirpes de Rhizobium japonicum e competitividade por sítios de infecção nodular em estirpes de soja. Agronomia Sulriograndense, Santa Maria, v. 16, p. 205-219, 1980.

SANTILLANA, N.; FREIRE, J. R. J.; SÁ, E. L. S.; SATO, M. Avaliação de estirpes de rizóbios para a produção de inoculantes para trevo vermelho. Revista Brasileira de Ciência do Solo, Campinas, v. 22, p. 231-237, 1998.

SANTOS, D. R. Seleção de estirpes deBradyrhizobium sp. para fixação de dinitrogênio em caupi (Vigna unguiculata (L.) Walp.), em solos salinizados do semiárido. 1987.98 f. Dissertação (Mestrado em Agronomia Ciência do Solo) - Universidade Federal Rural de Pernambuco, Recife, 1987.
THIES, J. E.; BOHLOOL, B. B.; SINGLETON, P. W. Subgroups of the cowpea miscellany: symbiotic specificity within Bradyrhizobium spp. for Vigna unguiculata, Phaseolus lunatus, Arachis hipogaea and Macroptilium atropurpureum. Applied and Environmental Microbiology, Washington, v. 57, p. 1540-1545, 1991a.

THIES, J. E.; SINGLETON, P. W.; BOHLOOL, B. B. Influence of the size of indigenous rhizobial populations on establishment and symbiotic performance of introduced rhizobia on field-grown legumes. Applied and Environmental Microbiology, Washington, v. 57, p. 19$28,1991 b$.

VINCENT, J. M. Manual for the practical study of root nodule bacteria. Oxford: Blackwell, 1970. 164 p.

WEAVER, R. W.; FREDERICK, L. R. Effect of inoculum rate on competitive nodulation of Glycine max L. Merril I: greenhouse studies. Agronomy Journal, Madison, v. 66, p. 229-232, 1974.

WEAVER, R. W.; FREDERICK, L. R. Rhizobium. In: PAGE, A. L.; MILLER, R. H.; KEENEY, D. R. (Ed.). Methods of soil analysis: chemical and microbiological properties. $2^{\text {nd }}$ ed. Madison: American Society of Agronomy, 1982. part 2, p. 1043-1070.

WOLFF, A. B.; STREIT, W.; KIPE-NOLT, J. A.; VARGAS, H.; WERNER, D. Competitiveness of Rhizobium leguminosarum bv. phaseoli strains in relation to environmental stress and plant defense mechanisms. Biology and Fertility of Soils, Berlin, v. 12, p. 170-176, 1991.

WOOD, M. A mechanism of aluminium toxicity to soil bacteria and possible ecological implications. In: DATE, R. A.; GRUNDON, N. J.; RAYMENT, G. E.; PROBERT, M. E. (Ed.). Plant-soil interactions at low pH: principles and management. Dordrecht: Kluwer, 1995. p. 173-179.

XAVIER, G. R.; MARTINS, L. M. V.; NEVES, M. C. P.; RUMJANEK, N. G. Edaphic factors as determinants for the distribution of intrinsic antibiotic resistance in a cowpea rhizobia population. Biology and Fertility of Soils, Berlin, v. 27, p. 386-392, 1998. 